\title{
Family is the most influential factor on happiness in high school students
}

\author{
Zhenzhu Wu \\ School of Psychology, South China Normal University, Guangzhou, China; 13660561379@139.com
}

Received 11 November 2013; revised 20 December 2013; accepted 29 December 2013

Copyright (C) 2014 Zhenzhu Wu. This is an open access article distributed under the Creative Commons Attribution License, which permits unrestricted use, distribution, and reproduction in any medium, provided the original work is properly cited. In accordance of the Creative Commons Attribution License all Copyrights (C) 2014 are reserved for SCIRP and the owner of the intellectual property Zhenzhu Wu. All Copyright (C) 2014 are guarded by law and by SCIRP as a guardian.

\section{ABSTRACT}

This study is to investigate the influential factors on the happiness of high school students with questionnaires in Guangdong province. The results show that family, health, character, life, ideal, learning, friend, education, leisure are the influential factors on happiness. Among these influential factors, family is the most influential factor on high school students' happiness, followed by health.

\section{KEYWORDS}

\section{High School Student; Happiness; Influential Factor; Family; Health}

\section{INTRODUCTION}

Happiness is an old but hot topic, and it is also one of important research issues in psychology field, and its research mainly included implications, levels, measurement methods, influential factors and promoted ways of happiness. The research objects are mainly concerned with the old men, adults and adolescents. These studies on adolescent students' happiness were mainly relative to college students, relative to middle school students less, and these studies mostly used scale to measure the levels or to know the influential factors on happiness. Middle school stage especially high school stage, is the critical period of the development in physiology and psychology. During this time students' self-emotional experiences are profound; emotions are increasingly richer; self-consciousness are largely developing, whereas their mental states are instability, so it is easier to bring about psychological health problems once they face with difficult choice or conflicts. Thus it is of a great significance for the study on high school students' happiness to rich psy- chological health education, and it is better to promote happiness research.

Some studies showed that character [1,2], life [3,4], social support [5-7], family [8,9], friendship [10], learning [11], health [12] were the influential factors on the happiness in high school students, in which researchers identified happiness by themselves, surveyed with scale questionnaires, and measured results with correlation analysis method, but couldn't reflect respondents' true view on the influencing factors and their contribution to happiness. This paper uses a question to know high school students' views on the influential factors on happiness. Our results may promote studies on happiness in middle school, and may provide support for their positive psychological health care practice.

\section{METHODS}

Using a multiple-choice questionnaire survey, as "Which has a/(have) great influence(s) on your happiness? Please list your choice(s) by great to small sort in order", we surveyed 2 high schools, 12 classes, 566 students, with the overall random sampling method in Guangdong province, to know high school students' views on the influential factors on happiness. We random chose two natural class each grade, the effective questionnaire was 546 , and the effective percent of recovery was $96.5 \%$. The subjects were 176 students in Grade One, 173 students in Grade Two, 197 students in Grade Three, and included male 215 and female 331, rural 277 and cities 266.

All survey data are input and sorted with Excel 2003 statistical software, all results are analyzed by SPSS 18.0 statistical software. These survey results were arranged in Tables 1-3 and Figure 1. Fortunately, the data in these tables show that the influence of each factor haven't been affected by the location of options, and shows that all sequences of options, such as the total number 
Table 1. The survey result of the question: Which have/(has a) great influence on your pearsonal happiness? Please list your choice(s) by great to small sort in order (Total number: 546, unit: \%, the percent of total number).

\begin{tabular}{|c|c|c|c|c|c|c|c|c|c|c|c|c|}
\hline \multirow{2}{*}{\multicolumn{2}{|c|}{ Options }} & \multicolumn{10}{|c|}{ The influence in position } & \multirow{3}{*}{$\begin{array}{c}\text { Total ratio } \\
96.9\end{array}$} \\
\hline & & \multirow{2}{*}{$\begin{array}{c}\text { the 1st } \\
53.7^{\star}\end{array}$} & \multirow{2}{*}{$\begin{array}{c}\text { the 2nd } \\
19.8\end{array}$} & \multirow{2}{*}{$\begin{array}{c}\text { the 3rd } \\
10.6\end{array}$} & \multirow{2}{*}{$\begin{array}{c}\text { the 4th } \\
5.5\end{array}$} & \multirow{2}{*}{$\begin{array}{c}\text { the 5th } \\
1.8\end{array}$} & \multirow{2}{*}{$\begin{array}{c}\text { the 6th } \\
3.1\end{array}$} & \multirow{2}{*}{$\begin{array}{c}\text { the 7th } \\
1.1\end{array}$} & \multirow{2}{*}{$\begin{array}{c}\text { the 8th } \\
0.5\end{array}$} & \multirow{2}{*}{$\begin{array}{c}\text { the 9th } \\
0.5\end{array}$} & \multirow{2}{*}{$\begin{array}{c}\text { the 10th } \\
0.2\end{array}$} & \\
\hline A & Family & & & & & & & & & & & \\
\hline B & Education & 1.3 & 3.5 & 6.0 & 9.0 & 10.8 & $11.9^{\star}$ & 9.9 & 9.7 & 6.6 & 0.4 & 68.5 \\
\hline $\mathrm{C}$ & Learning & 3.7 & 7.1 & $15.2^{\star}$ & 11.5 & 13.2 & 8.1 & 9.7 & 7.7 & 7.3 & 0.9 & 84.2 \\
\hline $\mathrm{D}$ & Ideal & 5.1 & 7.9 & 9.2 & 13.6 & $14.7^{\star}$ & 9.5 & 7.9 & 7.0 & 3.1 & 0.2 & 76.9 \\
\hline $\mathrm{E}$ & Life & 8.6 & $17.9^{\star}$ & 16.5 & 15.9 & 11.7 & 8.2 & 4.2 & 3.1 & 0.5 & 0 & 86.8 \\
\hline $\mathrm{F}$ & Friend & 1.5 & 17.2 & $18.5^{\star}$ & 16.5 & 14.3 & 10.4 & 7.7 & 3.7 & 1.3 & 0 & 90.8 \\
\hline G & Health & 13.4 & $14.3^{\star}$ & 13.9 & 12.6 & 10.1 & 7.9 & 7.1 & 3.8 & 0.9 & 0.2 & 84.1 \\
\hline $\mathrm{H}$ & Leisure & 1.1 & 1.1 & 0.9 & 3.1 & 4.6 & 8.4 & 10.8 & 14.8 & $20.3^{\star}$ & 1.5 & 65.8 \\
\hline I & Character & $10.1^{\star}$ & 9.5 & 6.8 & 7.5 & 7.0 & 9.0 & 8.6 & 9.5 & 6.8 & 0.7 & 75.3 \\
\hline $\mathrm{J}$ & others & 1.6 & 0.7 & 0.5 & 0.4 & 0.9 & 0.9 & 0.7 & 1.1 & 1.5 & $2.6^{\star}$ & 11.4 \\
\hline
\end{tabular}

${ }^{\star}$ The largest ratio value in the same option but different influence position.

Table 2. The result of different significant are arrayed by Pearson Chi-square test.

\begin{tabular}{cccc}
\hline & Chi-square & df & Sig \\
\hline the 1st & 1245.685 & 9 & 0.000 \\
the 2nd & 247.817 & 9 & 0.000 \\
the 3rd & 197.619 & 9 & 0.000 \\
the 4th & 151.372 & 9 & 0.000 \\
the 5th & 140.831 & 9 & 0.000 \\
the 6th & 69.175 & 9 & 0.000 \\
the 7th & 90.396 & 9 & 0.000 \\
the 8th & 157.804 & 9 & 0.000 \\
the 9th & 368.500 & 9 & 0.000 \\
the 10th & 38.030 & 7 & 0.000 \\
\hline
\end{tabular}

Table 3. The results of comparison between the sequence of the ratios in "the 1st" column with the location which has the largest ratio in each option.

\begin{tabular}{|c|c|c|c|c|c|c|c|c|c|c|}
\hline & A & $\mathrm{B}$ & $\mathrm{C}$ & $\mathrm{D}$ & $\mathrm{E}$ & $\mathrm{F}$ & G & $\mathrm{H}$ & I & $\mathrm{J}$ \\
\hline & Family & Education & Learning & Ideal & Life & Friend & Health & Leisure & Character & Others \\
\hline The sequence of the ratios in “the 1st”column & 1 & 9 & 6 & 5 & 4 & 8 & 2 & 10 & 3 & 7 \\
\hline The location which has the largest ratio in each option & 1 & 6 & 3 & 5 & 2 & 3 & 2 & 9 & 1 & 10 \\
\hline
\end{tabular}

sequence, the great influence number sequence and so on, are not necessarily related or invariably linked to the options (alphabetical) order, and those reflect that our results have certain reliability and validity.

\section{RESULTS}

According to the total ratio of each option in Table 1 , the options selected are in the following descending order: family (96.9\%), friend (90.8\%), life (86.8\%), learning $(84.2 \%)$, health $(84.1 \%)$, ideal $(76.9 \%)$, character (75.3\%), education $(68.5 \%)$, leisure $(65.8 \%)$, others (11.4\%). Among them, over $90 \%$ of students chose the option of family and the option of friend, about $85 \%$ of total students chose the option of life, learning, health, about $75 \%$ of total students chose the option of ideal, character, over $65 \%$ of total students chose the option of education, leisure. It shows that A-I options selected number ratio are more than $65 \%$ of total number, therefore, it shows that most high school students consider that family, health, character, life, ideal, learning, friend, education and leisure have great influence on happiness.

According to the results of "the 1st" column in Table 1 , it is known that the option of family has the largest proportion, followed in sequence by health (13.4\%), character $(10.1 \%)$, life $(8.6 \%)$, ideal $(5.1 \%)$, learning (3.7\%), others $(1.6 \%)$, friend $(1.5 \%)$, education $(1.3 \%)$ and leisure $(1.1 \%)$. The data shows that over $50 \%$ of students consider family is the most influential factor, which ratio is far more than other options', and about $10 \%$ of students think health, character or life is the most 

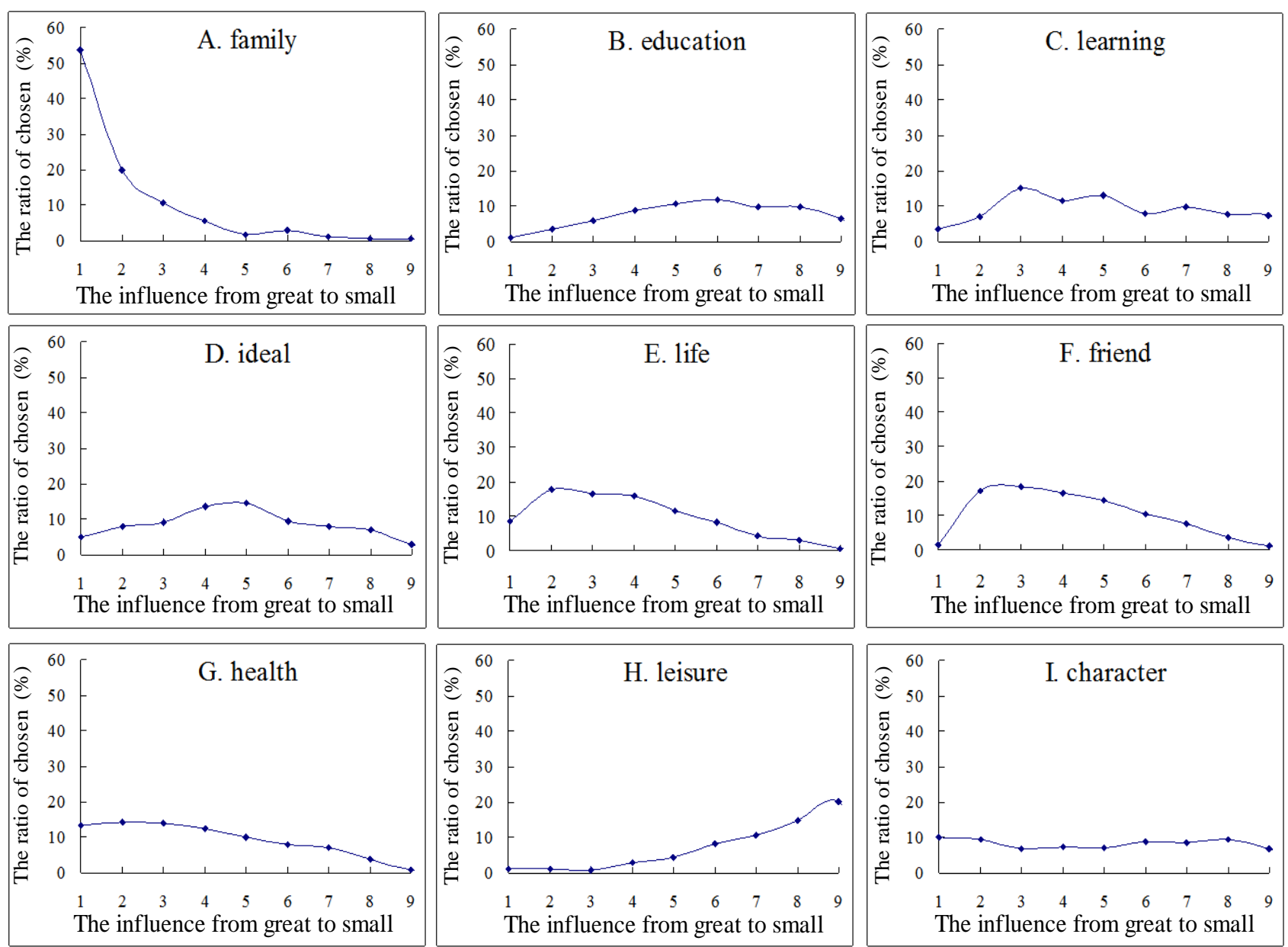

Figure 1. The ratio curves of each factor in different influential position.

influential factor, about $5 \%$ of students consider ideal or learning is the most influential factor, only about $1 \%$ of students think friend, education or leisure is the most influential factor, which of all the ratio are below "others" option. The results indicate that family, health, character and life have more influence on high school students' personal happiness, especially family is the most influential one, by contrast, the influences of ideal and learning are middle, the influences of friend, education and leisure are relatively minor, and the influence of leisure is the minimum. According to the results of Table 2, it is known that the difference of these influence factors on high school students is significant.

For further information, we compare the sequence of ratios in "the 1st" column with the location which has the largest ratio in each option, the result is seen in Table 3. The data in Table 3 show that all sorts of family and health completely consistent, respectively in the first position and the second, shows again that family and health have more influence on the happiness of high school students. And it also shows that the sort of ideal is also full consistent, is steady in the fifth.
In addition, the data in Table 3 showed that some options have the largest ration in the same position, e.g between family and character, life and health, learning and friend, corresponding to 1, 2, 3. It is clear combine to the results of the sequence of the ratios in "the 1st" column that character has less influence on high school students happiness than family, as well, life's influence is less than health's, and friend's is less than learning's.

To know whether these influential factors have individual differences in the high school student group or not, we draw charts in Figure 1. As shown in Figure 1, the higher the starting point in curve, the more influence on happiness. It is clear from Figure 1 that the starting point in family, health, life or character curve is high, the starting point in ideal or learning curve is middle, and the starting point in education, friend or leisure curve is very low, that reflects family, health, life and character have greater influence on happiness, but the influences of education, friend and leisure on happiness is relatively small.

As shown in Figure 1, the curve of character is nearly linear form, the curve of learning is more than a wavy peak, and both keep on a high level, reflect that there are 
remarkable difference for high school students' views on the influence of character or learning on happiness, and it shows that the influence of character or learning on the high school students' happiness has significant individual differences. The curves of other factors all have only a peak, reflect the influence of family, education, ideal, life, friends, health or leisure on happiness have less significant individual difference. But the curves have different trend, for example, the curve of family or health have a significant decline trend, shows that the influence of family or health has a greater influence on happiness, and the curve of family decline markedly, reflect family has the most influence on high school students' happiness, followed by health. In contrast, the curve of leisure or education show an upward tendency, especially leisure curve is "J" type, show that the influence of leisure or education is relatively small, while the influence of leisure is the smallest.

Stated thus, there are many influential factors on high school students' happiness, including family, health, character, life, ideal, learning, friend, education, leisure. Among them, family is the most influential one, followed by health. The influences of various factors on happiness are in the following descending order: family $>$ health $>$ character $>$ life $>$ ideal $>$ learning $>$ friend $>$ education $>$ leisure.

\section{DISCUSSION}

Shi Guo Xing's study [13] (2006) indicates that students grown up in harmonious family are happier, they have more positive emotions and less negative emotions, their life satisfaction and self-efficacy are relatively higher, the study also shows that harmonious home environment conducive to students grow up happily, their results are consistent with ours.

Xiang Man-jun’s study [14] (1995) shows that health is the most influential factor of life satisfaction for aged men, followed by family. Our results show that family is the most influential factor on happiness for high school students, followed by health. These results reflect that family and health both have more influences on happiness during the whole life whether the man is young or old, though the influence of factor will change with age change.

We think the influences of family and health on happiness have difference in age, maybe because the attention of things are changed when they are in different age stage. Health is the most concern for the old men, their bodies can't resist to decline with the age growth, which directly affect the quality of life, thus affect their happy experience. On the other hand, old men often compare the current body condition with the health status of young, and they are anxious about the changes of their bodies, which significantly increase their negative emotions and reduce their sense of happy, so as to health become the most influential factor of their happiness.

However, adolescents are in growth stage, their bodies are increasingly strong and healthy, they are full of vitality, so as to have more energies to achieve their potential and to pursue their dreams. For adolescents who haven't economic conditions to live on themselves, family is the moste important and attention thing for them. For adolescent, family is not only the source of life and love, but also the main support sources of physical, economic, spiritual and emotional supports, family is the first and important place to link with society, especially play an important role in the develop of communication, problem solving, behavior control, emotional response and so on. Moreover, parents are irreplaceable for child in the course of growth. We know parents are the most reliable and most security for child, parents are the early learning models, parents' criticism or praise can directly affect child's behavior and self-evaluation, the expectations of parents also affect child to establish long-term goal and short-term goals. Besides, family income and social status will directly impact on child's life quality. In addition, the influence of parents is a major force in the development of character, for example, parents' educations, including education levels, education attitude and education method etc, have great influence on character and its formation for child, which, in turn, has an impact on happy experience and feelings in life. Moreover, adolescents are not mature enough to adapt themselves to environmental change. Each change or fluctuation in family, not only directly affect the quality of life, but also project to child's emotion, and the fluctuation range of emotion will be enlarged. In addition, family is the base unit of the society, Chinese is very family-oriented national, family occupied a very important position in their mind, they attach great importance to family, and perhaps these Chinese family cultures is one reason for the influence of family on happiness in high school students.

High school students mainly live in family or school, their social relations mainly are family relations and friends, their life circle is relatively simple. Our results show that $90 \%$ of students agree on friend is one of influential factor, its total number is second only to family, reflect that high school students general recognition to social relationship is the important influential factor on happiness. As grown up, high school student self consciousness developed, independence strengthen also increased, the talk among friends increased with the decrease of family chat, and the heart-to-heart talk between friends play an important role to low their pressure, relieve worries, improve positive emotion. As one of important social relations, friends have affect on their sense of happiness and provide them with social support. 
We find there is large different between family and friend, which affect on high school students' happiness, the influence of friend is far lower than the influence of family, and only $1.4 \%$ of students consider friend is the most influential factor. We consider social support provided by friends, mainly include spiritual encouragement, emotional comforts, spiritual aspects, but less material or economic aid, family is the mainly social support when adolescents face with some economic and life difficult. Maybe that is the main reason why the influence of friend on happiness is relatively less. In addition, Family relationship has remained relatively stable and firm, friend relationship is changing with moving to new environment or studying at new school, maybe that is one reason why the influences of friend is lower than the influence of family on happiness in high school students.

Our results show that more than $70 \%$ of students deem that character has impact on their happiness, and 10\% of them deem that character is the most influential factor. It seems to students that happiness has a personality trait. For example, optimists live a positive life, their happy thresholds are low so that it is easy to satisfy and happy, and they maintain a positive mental outlook despite all the difficulties. But pessimists live a negative life, and their happy threshold values are relatively high, so it is not easy to be stimulated by outsides, they sink into depression and despair when they face various difficulties. These results are in good agreement with those obtained by Dinner and Xia Jun-Li. As Dinner [15] has pointed out that personality has stable and effective prediction for happiness, and Xia Jun-Li [1] has pointed out that personality is the valid predictive variables for happiness in high school students, and its effect on predictive for the emotional states is maximum.

In addition, the chosen number of character option in different positions is equal, reflect that high school students know that the character is intrinsic, their different reactions steady reflected their very different characters. Character changes small in all life, and it can't cause the happy experience wide fluctuations, but the influence of family or health on happiness is intuitive and strong. Students who have a harmonious family life and have a strong healthy body, no matter he is introverted or extroverted, they live more joy and happier but take on a different from, extroverts tend to share their happiness with others, while introverts like quietly enjoy their happiness. And students grown up with family strife or suffered from a serious illness, even if having a bright character, they also could not say they are very happy.

Our result showed that more than $80 \%$ of students considered learning had great influence on their happiness, this result is concordant with some domestic scholars' $[11,16]$ results. These reflect that in high school, most of students are faced with the puzzles caused by the gap between academic performance and learning expectation, the pressures of entering universities and so on, and they are dispirited by these questions. In addition, most of them hold the ideal of entering university to study, even if teachers and parents don't give them any pressure, they also attach great importance to study, the academic record will directly cause a surge of emotion, thus affect the happy experience. Our results also showed that $3.5 \%$ of them regard learning as the most influential factor of happiness and the whole life, and showed that $7.1 \%$ of them think learning have less impact on their happiness, we presume that they become disinterested in learning, the numbers of above in all are over $10 \%$, it is a matter worthy of our attention.

Our results showed that more than $60 \%$ of students deemed education to have a great influence on their personal happiness, the influence of education is only above leisure's. It is assumed that education is equal to school education, classroom teaching or theory teaching, which mainly is to enhance the cognitive level, widen personal vision and promote mental development. For high school students, Education should include family education and school education. At present, China's basic education is equal to each child, but children have different degree of happiness, to some extent, family education is more related to happiness than school education, and it is very important for adolescent to receive good family education. Furnham's [17] (2000) study indicates that the way child was brought up, is one of the main and the most powerful factors predicting child's happiness. Huang Xiao-Yan [18] (2007) pointed out that students who received democratic family education were significantly happier than those who received chastise family education, so it is clear that family education is very important for adolescents to be happy. Fortunately, parents have gradually pay attention to child's early education, but parents pay more attention to child's academic records as he grows up to high school stage. Thus, how to improve the quality and efficiency of family education needs further study.

\section{CONCLUSIONS}

There are many influential factors on high school students' happiness, including family, health, character, life, ideal, learning, friend, education, leisure. Among them, family is the most influential one, followed by health. The influences of various factors on happiness are in the following descending order: family $>$ health $>$ character $>$ life $>$ ideal $>$ learning $>$ friend $>$ education $>$ leisure.

The happiness of high school students is not only influenced by personal factors such as health, character and ideal, but also influenced by external factors such as 
family, friends, life, learning, education and leisure. High school students' happiness status is person, family and school, the result of joint action. Among these factors, family is the most influential one. Therefore, for improving adolescent' happiness, parents should be better cooperative with school, try their best to give children more pleasure of life and happiness of learning environment, and make a concerted effort to build up children's health, to improve children's IQ and EQ, and to strong children's will.

According to the above analysis, several ways for improving high school students' happiness efficiently are put forward: 1) Living in a warm and harmonious family, establishing a close parent-child relationship; 2) Paying more attention to family education, praising highly democratic and admiration type of education mode; 3) Enhancing taking exercise, boosting physical and emotional health; 4) Culturing positive character, and improving the ability to alleviate negative emotions; 5) Giving guide to set up ideal and goal; 6) Treating correctly the relationship between learning and life; 7) Making faithful friends and keeping good company.

\section{REFERENCES}

[1] Xia, J.-L. (2006) The Relationship between personality and subjective well-being of senior high school students. Journal of Fujian Normal University (Philosophy and Social Sciences Edition), 4, 159-162.

[2] Tan, Z.-J., Nie, Y.-G. and Luo, C.-X. (2010) The relationship between big five personality and subjective wellbeing of middle school students. Journal of Inner Mongolia Normal University (Educational Science), 12, 5156.

[3] Xiao, J.-W. and Shi, G.-X. (2005) A relative study of the senior high school students' daily event, mental health, and sense of happiness. Journal of Hebei Normal University (Educational Science Edition), 02, 75-78.

[4] Wang, H. (2005) A study of the influence of personality, values and life events on high school students' subjective well-being. Shaanxi Normal University.

[5] Xin, Z.-Q. and Chi, L.-P. (2001) The relationship between happiness and social support. Acta Psychologica Sinica, 5,

$$
\text { 442-447. }
$$

[6] Yang, X.-H. (2005) Study on influence of senior high school students' social support to subjective well-being. Nanjing Normal University.

[7] Ceng, L. and Liao, F.-L. (2009) A study on the relationship among coping style, social support and subjective well-being in high school students. Journal of Capital Normal University (Social Sciences Edition), S4, 76-82.

[8] Zheng, Z.-P. (2011) The research on the relationship between family environment, parenting style and adolescent subjective well-being. Tianjin Normal University.

[9] Gu, H.-Y. (2009) Study on the relationships between family function and subjective well-being of adolescent. Northeast Normal University.

[10] Dai, Q.-Y. (2005) The relationship between adolescents' friendship and subjective Well-being. East China Normal University.

[11] Zhao, S.-Y., Cai, T.-S., Zeng, X.-Z. and Chen, Z.-J. (2011) Subjective well-being of senior high school students and its relationship to school-work achievement. Chinese Journal of Clinical Psychology, 01, 128-129.

[12] Chen, Z.-S. and Ji, L. (2006) The effects of physical exercise on subjective well-being of senior high school students and their psychological mechanism. Acta Psychologica Sinica, 38, 562-575.

[13] Shi, G.-X. and Yang, H.-R. (2006) Subjective well-being of middle school students. Chinese Mental Health Journal, 20, 238-241.

[14] Xiang, M.-J., Wu, X.-G. and Liu, X.-H. (1995) Life satisfacition and factors related to elderly citizens in Beijing. Acta Psychologica Sinica, 04, 395-399.

[15] Diener, E. and Lucas, R. (1999) Personality and subjective well-being. In: Kahneman, D., Diener, E. and Schwarz, N., Eds., Foundations of Hedonic Psychology, Russell Sage, New York, 213-229.

[16] Wei, X. (2012) A Research on the relationship between academic achievement and subjective well-being in high school students. Magnificent Writing, 17, 16.

[17] Furnham, A. and Cheng, H. (2000) Perceived parental behavior, self-esteem and happiness. Social Psychiatry and Psychiatric Epidemiology, 35, 463-470.

[18] Huang, X.-Y. (2007) Correlation of personality, parenting Style, life event, coping style and subjective well-being in senior middle school students. China Medical University. 